\title{
Increasing role of Anopheles funestus and Anopheles arabiensis in malaria transmission in the Kilombero Valley, Tanzania
}

Dickson W Lwetoijera ${ }^{1,2^{*}}$, Caroline Harris ${ }^{3}$, Samson S Kiware ${ }^{1,4}$, Stefan Dongus ${ }^{1,5}$, Gregor J Devine ${ }^{6}$, Philip J McCall ${ }^{2}$ and Silas Majambere ${ }^{1,2}$

\begin{abstract}
Background: In order to sustain the gains achieved by current malaria control strategies, robust surveillance systems that monitor dynamics of vectors and their roles in malaria transmission over time are essential. This longitudinal study demonstrates the trends in malaria vector dynamics and their relative contribution to malaria transmission in hyperendemic transmission settings in Tanzania.

Methods: The study was conducted in two villages within the Kilombero Valley, in rural Tanzania for five consecutive years (2008-2012). Seventy-two houses were selected per village and each house was sampled for mosquitoes monthly using a CDC light trap. Collected mosquitoes were assessed for species identity and sporozoite infection status using PCR and ELISA, respectively. Anopheles funestus and Anopheles arabiensis susceptibility to insecticides was assessed using WHO guidelines.

Results: A total of 100,810 malaria vectors were collected, of which $76 \%$ were Anopheles gambiae s. I. and $24 \%$ were An. funestus. Of all An. funestus samples that amplified with PCR $(n=2,737), 97 \%$ were An. funestus s.S., $2 \%$ were Anopheles rivorulum and 1\% Anopheles leesoni. Whereas for An. gambiae s.l. $(n=8,117), 93 \%$ were An. arabiensis and $7 \%$ were Anopheles gambiae s.s. The proportion of An. gambiae s.s. identified by PCR $(2,924)$ declined from $0.2 \%$ in the year 2008 to undetectable levels in 2012. Malaria transmission intensity significantly decreased from an EIR of $78.14 \mathrm{infectious} \mathrm{bites/person/year} \mathrm{in} 2008$ to $35 \mathrm{ib} / \mathrm{p} / \mathrm{yr}$ in 2011 but rebounded to $226 \mathrm{ib} / \mathrm{p} / \mathrm{yr}$ in 2012 coinciding with an increased role of An. funestus in malaria transmission. Insecticide susceptibility tests indicated high levels of resistance in An. funestus against deltamethrin (87\%), permethrin (65\%), lambda cyhalothrin (74\%), bendiocarb (65\%), and DDT (66\%). Similarly, An. arabiensis showed insecticide resistance to deltamethrin (64\%), permethrin (77\%) and lambda cyhalothrin (42\%) in 2014.
\end{abstract}

Conclusion: The results indicate the continuing role of An. arabiensis and the increasing importance of An. funestus in malaria transmission, and pyrethroid resistance development in both species. Complementary vector control and surveillance tools are needed that target the ecology, behaviour and insecticide resistance management of these vector species, in order to preserve the efficacy of LLINS.

Keywords: Malaria, Anopheles, Transmission, Vector, Surveillance, Gambiae, Arabiensis, Funestus, Season, Insecticide, Susceptibility, EIR, Kilombero, Tanzania

\footnotetext{
*Correspondence: dwilson@ihi.or.tz

${ }^{1}$ Environmental Health and Ecological Sciences Thematic Group, Ifakara

Health Institute, PO Box 53, Ifakara, Tanzania

${ }^{2}$ Vector Biology Department, Liverpool School of Tropical Medicine,

Pembroke Place, Liverpool L3 5QA, UK

Full list of author information is available at the end of the article
} 


\section{Background}

Malaria transmission in humans is sustained through vector-human interactions [1] and vector control interventions, such as long-lasting, insecticidal nets (LLINs), aim to break this interaction. Major promotion of LLINs in recent years has resulted in average household ownership rates and usage of LLINs of approximately 42 and $36 \%$, respectively, in sub-Saharan Africa [2]. In mainland Tanzania, a recent report by the Tanzania HIV and Malaria Indicator Survey (THMIS) indicates that above average LLIN ownership and usage (approximately 90 and $66 \%$, respectively) was associated with improved malaria control and overall reduction in malaria prevalence [3].

One outcome of LLIN use is that, by limiting availability of human hosts [4-6], vector species composition in any given area can change considerably after a long period of LLIN use. Anopheles gambiae sensu stricto, Anopheles arabiensis and Anopheles funestus are the primary malaria vectors in sub-Saharan Africa [7,8], often occurring sympatrically [9]. Anopheles gambiae s.s. is often regarded as the most important vector species across Africa [9-11] and, because of its almost entirely anthropophagic and endophilic behaviour, it is the species that has been targeted most effectively by LLINs.

However, in some locations, populations of An. gambiae s.s. have developed insecticide resistance and it continues to be the dominant vector $[12,13]$. In other locations, $A n$. gambiae s.s. populations have crashed and the relative importance of the remaining vector species has shifted, with $A n$. arabiensis becoming the major malaria vector $[4,5,11]$.

Since single populations of An. arabiensis can exhibit a range of behaviours, biting and resting indoors as well as outdoors and feeding on both humans and animals, interventions that optimally target indoor resting and biting vectors often impact far less on this species [11,14-17]. The primary vector of the An. funestus complex, An. funestus is also a very anthropophilic and endophilic mosquito and it too can be a highly efficient malaria vector $[10,18,19]$.

Kilombero Valley in southern Tanzania has been subject to a large number of studies on malaria epidemiology, dating back many years, with malaria parasite prevalence rates of up to $70 \%$ and an entomological inoculation rate (EIR) of 300 infectious bites per person per year (ib/p/yr) being recorded in the 1990s, the period before the introduction of bed nets [20]. Following the scaling up of untreated nets in the early 2000 s [21] and insecticide-treated bed nets (ITNs) and LLINs from 2004 to 2011 [22-24], a continuous decline in malaria vector numbers and malaria transmission has been seen [3,12]. Although the populations of An. gambiae s.s. are significantly dwindling in southern and other parts of Tanzania [12], the remaining populations of $A n$. arabiensis and $A n$. funestus appears to have shifted their blood-feeding periodicity to optimize their chances to obtain blood meal from their preferred hosts even in the time of low LLIN coverage [25]. It is however suggested that prolonged, widespread use of LLINs is likely to favour outdoor and early biting, either as an expression of the mosquito's innate phenotypic plasticity or possibly as a heritable, selectable trait that might be expected to increase in frequency [25].

The malaria vector populations in this area are subject to ongoing rigorous monitoring and herein five years of data to the end of 2012 are reported; describing changes in vector species composition and relative abundance, insecticide susceptibility and their contribution to malaria transmission following the years of widespread LLIN use since first introduced in 2004.

\section{Methods}

\section{Study site}

The study was carried out in Namwawala $\left(8.154425^{\circ} \mathrm{S}\right.$ and $\left.36.393005^{\circ} \mathrm{E}\right)$ and Idete $\left(8.098190^{\circ} \mathrm{S}\right.$ and $36.510350^{\circ}$ E) villages (Figure 1) located in the flood plain of the Kilombero River $\left(8.1^{\circ} \mathrm{S}\right.$ and $\left.36.6^{\circ} \mathrm{E}\right)$ in southeastern Tanzania. The epidemiology of malaria transmission and associated vector species composition within these villages has been documented over many years [21,25]. Both villages experience an annual rainy season (January-May) and the main crops are rice and maize. Both villages are similar in size (Namwawala $=844$ and Idete $=804)$ and approximately $92 \%$ of community members sleep under an ITN or LLIN [12].

\section{Study design}

This study was conducted over five years between January 2008 and December 2012. A total of 72 houses from each village were randomly selected from the Ifakara Health Institute (IHI) Demographic Surveillance System household list [26]. All selected houses were geolocated using a handheld GPS (eTrex, Vista, Garmin, USA). Mosquitoes were sampled in every house each month during 2008, 2011 and 2012 and for six months from January to June in 2009 and July to December in 2010.

\section{Mosquito sampling and processing}

Mosquitoes were sampled using miniature Center for Disease Control (CDC) light traps (model 512, USA). One CDC light trap was used overnight per house, placed 1-1.5 $\mathrm{m}$ from the fan above the ground close to the foot end of an occupied bed, and left to run for 12 hours (19.00-07.00) [27,28]. For every participating house, one LLIN (Olyset, A to Z Textiles Mills, Arusha, Tanzania) was provided to protect the bed occupant where the CDC trap was set. The following morning, CDC light traps were collected and mosquitoes killed 


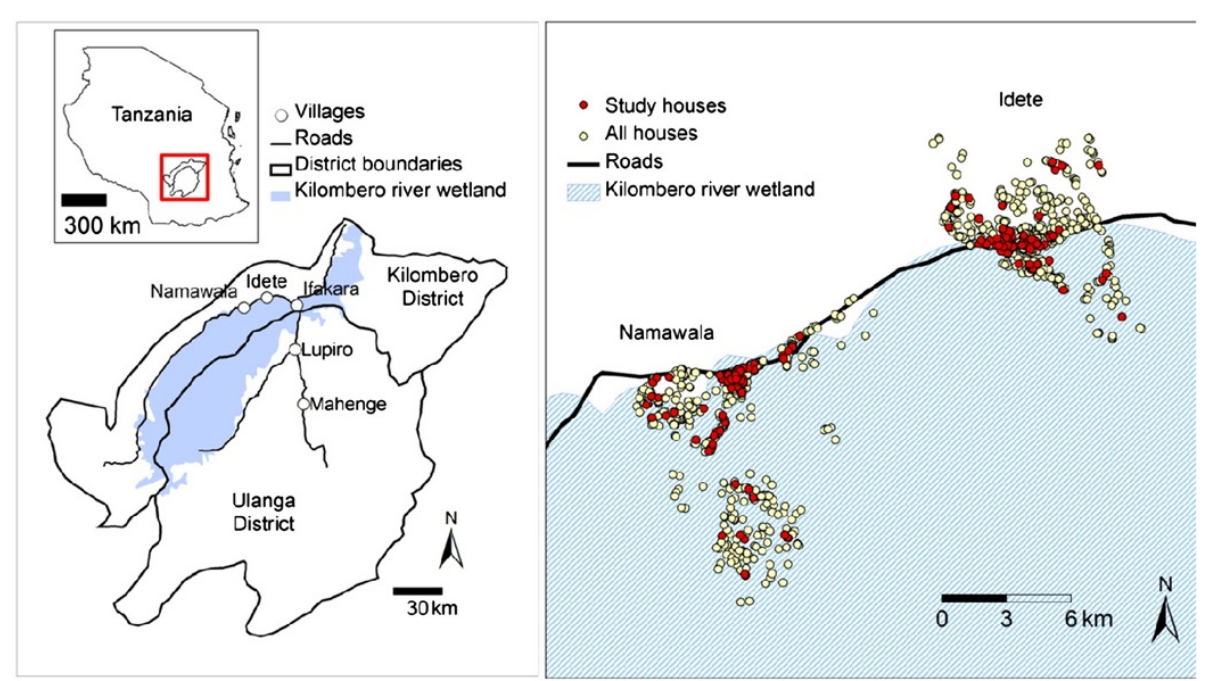

Figure 1 A map showing sentinel houses for mosquito sampling in Idete and Namwawala villages, within Kilombero Valley, in Kilombero district, Tanzania.

using chloroform, and identified in the field using a morphological key [18]. Female mosquitoes were classified as being unfed, partially fed, fully fed or gravid. Subsamples of five mosquitoes from each trap for An. arabiensis and An. funestus species were individually stored inside a tube containing cotton wool and silica gel beneath for further individual molecular species identification using polymerase chain reaction (PCR) assay for the An. gambiae complex [29] and An. funestus group [30] and sporozoite infection status using enzyme-linked immunosorbent assay (ELISA) [31] in the laboratory (species identification for the An. funestus group did not begin until 2009).

All the sorting information and laboratory analysis results were recorded using designated data collection forms for entomological studies (Kiware et al., unpublished). In addition, variations in malaria transmission by different vector species over time were assessed and compared using the annual EIR calculated by biting rate (total collections/trap nights/year) and the proportion of females infected with sporozoites [32]. Monthly average rainfall data for 2008-2011 were obtained from the Kilombero Valley Teak Company (approximately $15 \mathrm{~km}$ from Idete village), and data for year 2012 data were obtained using rain gauges installed in Namwawala village.

\section{Insecticide susceptibility tests}

Following significant increase in An. funestus population in 2012, despite extensive usage of LLIN in the study area, it was unclear whether this was due to its reduced susceptibility to the insecticides used in LLINs. The tests were conducted using WHO standard procedures and test kits for adult female mosquitoes of An. arabiensis and An. funestus [33] in Namwawala villages from January to
June 2013. As the confirmatory process, the biossays were repeated in June 2014 for both species.

Five classes of insecticides currently recommended for vector control were tested using discriminating concentrations impregnated in pre-prepared test papers as follows: deltamethrin $(0.05 \%)$, permethrin $(0.75 \%)$, lambda cyhalothrin $(0.05 \%)$, bendiocarb $(0.1 \%)$, and DDT $(4 \%)$. Unfed female wild An. funestus collected using CDC light traps were used for insecticide exposure bioassays, as recommended by $\mathrm{WHO}$ for this difficult-to-colonize species [33]. However, this method is limited by greater variation in susceptibility due to unknown age differences between test mosquitoes, it is simple to carry in the field with minimal infrastructure and test mosquitoes highly representative of the natural population [33].

Prior to exposure, morphologically identified mosquitoes were maintained on $10 \%$ glucose solution for at least five hours prior to testing; whereas, for An. arabiensis, F1 female mosquitoes two to three days old (recommended age group) were used for bioassays from reared Anopheles larvae collected from the breeding habitats in the study sites $[34,35]$. Species identification was carried out after bioassays on dead mosquitoes using PCR.

A total of 100 mosquitoes were exposed per discriminating concentration in five replicates of 20 mosquitoes each, and compared to a control with same number of mosquitoes per replicate. In an exposure tube, mosquitoes were held for a total of one hour in intervals of $10,15,20,30$, 40, 50, and 60 minutes. After the first hour of exposure, mosquitoes were transferred to non-insecticide treated, clean, holding tubes and observed for a further 20 minutes [33]. After 80 minutes (initial $60 \mathrm{~min}+$ further $20 \mathrm{~min}$ ) of knockdown monitoring, all mosquitoes were transferred 
to non-insecticide treated, clean, holding tubes and kept for 24 hours and provided with $10 \%$ glucose solution, after which mortality was monitored and recorded. All these procedures were performed in the field under average ambient temperatures of $26 \pm 2^{\circ} \mathrm{C}$ and a relative humidity of $78 \pm 3 \%$ in both bioassay rounds. Percentage knockdown in the observed mosquitoes was recorded immediately for each time interval, and mosquito mortality in each bioassay was expressed as the proportion of dead mosquitoes to total exposed, for each tested insecticide. Execution and interpretation followed recently updated WHO test procedures for insecticide resistance monitoring in malaria vector mosquitoes [33].

\section{Statistical analyses}

Only data pertaining to An. gambiae s.l. and An. funestus were analysed, using SPSS version 20 (SPSS Inc, Chicago, USA). Data were fitted with generalized linear models (GLMs) using a negative binomial distribution with loglink function, and relative rates (RR) with 95\% confidence intervals calculated to estimate yearly mean mosquito catches, relative to the reference year. Species (An. gambiae s.l. and An. funestus) were treated as predictors and total number of mosquitoes as a dependent variable; the statistical differences in dependent variables was evaluated as a function of villages (Idete and Namwawala), seasons (wet and dry) and years (2008-2012).

Insecticide susceptibility test biossay data were considered for each diagnostic concentration and year of testing. Mortality was calculated as the percentage of mosquitoes dead post 24 hours' exposure to insecticide, and the results were assessed according to WHO testing procedure for insecticide resistance monitoring in malaria vectors [33]. Mortality rates between 98 and 100\% indicate full susceptibility, $90-97 \%$ is suggestive of resistance and requires further investigation, and mortality rates less than $90 \%$ confirm the existence of resistance.

\section{Ethical considerations}

The study approval was granted by the Ifakara Health Institutional Review Board (IHRDC/IRB/No.A-32) and the National Institute of Medical Research (NIMR/HQ/ R.8a/Vol. IX/764). On first visiting each house, the benefits and possible risks associated with the study were explained to the house occupants and informed consent to proceed was requested. After consenting, the head of the house was asked to sign two copies of the informed consent forms, (retained by the head of the house and the study investigator).

\section{Results}

\section{Relative abundance of malaria vector species}

During the five consecutive years of sampling with CDC light traps in sentinel houses, a total of 100,810 malaria vectors were collected of which $76 \%$ were Anopheles gambiae sensu lato and $24 \%$ were An. funestus. In each of the first four years (2008-2011), the proportion of An. gambiae s.l. was significantly higher than An. funestus in both study villages $(p<0.0001)$ : proportions in total catches in Namwawala were $94 \%(40,028)$ and $6 \%(2,398)$, and in Idete were $87 \%(24,869)$ and $13 \%(3,730)$ for An. gambiae s.l. and An. funestus, respectively. However, in 2012, the proportion of total catch of An. funestus was significantly higher than $A n$. gambiae s.l. in both villages: $42 \%(6,622)$ and $58 \%(8,953)$ in Namwawala and 35\% $(4,479)$ and $65 \%(8,447)$ in Idete for An. gambiae s.l. and An. funestus, respectively, (RR (95\% CI) = 1.35 (1.23-1.49), $p<0.0001)$.

A total of $8,117 A n$. gambiae s.l. were successfully identified by PCR and comprised 93\% An. arabiensis (n $=7,549)$ and $7 \%$ An. gambiae s.s. $(\mathrm{n}=568)$. The relative proportions of the species were similar in Idete (An. arabiensis $96 \%(\mathrm{n}=3,610)$, An. gambiae s.s. $4 \%(\mathrm{n}=151)$ and in Namwawala 90\% ( $\mathrm{n}=3,900)$ An. arabiensis, $10 \%$ ( $\mathrm{n}=456)$ An. gambiae s.s.. However, the relative proportion between the two sibling species was changing over time, with significant decrease of An. gambiae s.s. from $14 \%(409 / 2,924)$ in year 2008 to disappearance 0\% (0/ 1,362 ) in year 2012, compared to An. arabiensis increasing from $86 \%$ in 2008 to $100 \%$ in 2012 (Table 1).

Of the 2,737 An. funestus samples that were identified by PCR, 97\% were An. funestus s.s. ( $\mathrm{n}=2,655), 2 \%$ were Anopheles rivorulum $(\mathrm{n}=55)$ and $1 \%$ Anopheles leesoni $(\mathrm{n}=27)$. The species composition of $A n$. funestus in Idete was $98 \%(\mathrm{n}=1,554)$ An. funestus s.s, $1.5 \%(\mathrm{n}=23)$ $A n$. rivorulum and $0.4 \%(\mathrm{n}=6) A n$. leesoni. In Namwawala it was $98 \%(\mathrm{n}=1,133)$ An. funestus s.s., $0.6 \%(\mathrm{n}=7)$ An. rivorulum and 1.2\% ( $\mathrm{n}=14)$ An. leesoni, (Table 1).

\section{Seasonal variation in vector abundance}

During the study, the period from January to May was categorized as the wet season, receiving an average $(+\mathrm{SD})$ of rainfall of $281+178 \mathrm{~mm} /$ month, and JuneDecember as the dry season, with an average of rainfall of $24+66 \mathrm{~mm} /$ month (Figure 2). The abundance of both An. gambiae s.l. and An. funestus peaked in the wet season in both villages. The mean number (+SD) of An. gambiae s.l. caught per trap per night during the wet season was $19+48$ and $32+110$, whereas in the dry season it decreased to $0.86+5.7$ and $1.1+5.8$ at Idete and Namwawala, respectively. Furthermore, An. gambaie s.s. was only present in the wet season in the first three years (2008-2009/10) before its disappearance in 2011/ 12, compared to its sibling species $A n$. arabiensis, which was found to exist in both season, similar to An. funestus s.s., a dominating member of $A n$. funestus group.

The mean number of $A n$. funestus per trap per night in the wet and dry season of the first four years of study 
Table 1 Malaria vector composition, sporozoite prevalence (S), biting rate (B) and entomological inoculation (EIR) for Anopheles gambiae S.s., Anopheles arabiensis and Anopheles funestus and their overall estimated yearly contribution to malaria transmission from year 2008-2012 in the study area

\begin{tabular}{|c|c|c|c|c|}
\hline Species & 2008 & $2009 / 10$ & 2011 & 2012 \\
\hline \multicolumn{5}{|c|}{ An. gambiae complex sibling species proportion } \\
\hline An. gambiae s.s. & 0.14 & 0.15 & 0.002 & 0 \\
\hline An. arabiensis & 0.86 & 0.85 & 0.998 & 1 \\
\hline No. of PCR amplifications & 2,924 & 1,307 & 2,542 & 1,362 \\
\hline \multicolumn{5}{|c|}{ An. funestus group sibling species proportion } \\
\hline An. funestus s.s. & - & 0.887 & 0.956 & 1 \\
\hline An. rivulorum & - & 0.013 & 0.021 & 0 \\
\hline An. leesoni & - & 0 & 0.023 & 0 \\
\hline An. parensis & - & 0 & 0.001 & 0 \\
\hline No. of PCR amplifications & - & 330 & 880 & 1,527 \\
\hline \multicolumn{5}{|c|}{ Sporozoite prevalence $(\mathrm{S} ; \%)$} \\
\hline An. gambiae s.s. & 1.18 & 0.04 & 0 & 0 \\
\hline An. arabiensis & 0.16 & 0.36 & 0.07 & 1.47 \\
\hline An. funestus & 1.71 & 0 & 0.43 & 2.20 \\
\hline \multicolumn{5}{|l|}{ Biting rate $(B ; b / p / n)$} \\
\hline An. gambiae s.s. & 8.52 & 6.05 & 0.04 & 0 \\
\hline An. arabiensis & 52.37 & 35.51 & 59.74 & 20.70 \\
\hline An. funestus & 1.74 & 12.84 & 10.09 & 14.31 \\
\hline \multicolumn{5}{|c|}{ Entomological Inoculation Rate (EIR; ib/p/y) } \\
\hline An. gambiae s.s. & 36.70 & 1.61 & 0 & 0 \\
\hline An. arabiensis & 30.58 & 55.51 & 15.17 & 110.90 \\
\hline An. funestus & 10.86 & 0 & 15.58 & 115.10 \\
\hline Total & 78.14 & 57.12 & 31.05 & 226.0 \\
\hline
\end{tabular}

Note: Sporozoite prevalence $=$ Number of positive sporozoite mosquitoes/total tested; Biting rate $=$ Total collections/trap nights/calibration factor, 0.3 for $A n$. gambiae complex, and 0.68 for An. funestus [21]; EIR $=\mathrm{S} \times \mathrm{B} \times 365$.

(2008-2011) was consistently similar in both villages. In the wet season, the mean catches $(+\mathrm{SD})$ were $1.23+4.7$ in $2008,2.15+7.5$ in $2009 / 10,0.64+1.9$ in 2011 compared to $1.15+5.2,0.77+4.3$ and $1.62+5.52$ of the respective years in the dry season. In 2012, the mean catch of $A n$. funestus, both in wet and dry seasons, was approximately six times significantly higher than in the previous years $(p<0.0001): 11.75+45.8$ and $8.3+25.6$ of wet and dry season, respectively.

\section{Malaria transmission}

A total of 10,138 individual mosquitoes (530 An. gambiae s.s., 7,130 An. arabiensis and 2,478 An. funestus s.s.) were screened for Plasmodium falciparum sporozoites of which 75 were positive $(0.74 \%$ sporozoite prevalence). Although An. gambiae s.s. was the major malaria vector with a sporozoite prevalence of $1.18 \%$ in 2008 , its dominance decreased with time to zero in 2011 and 2012, following its control to undetectable levels. Conversely, the importance of An. arabiensis and An. funestus s.s was increasing with time from a sporozoite prevalence of $0.16 \%$ in 2008 to $1.47 \%$ in 2012 for An. arabiensis, and from $1.71 \%$ in 2008 to $2.2 \%$ in 2012 for An. funestus s.s.

Similarly, the EIR of An. gambiae s.s. decreased drastically from $30.70 \mathrm{ib} / \mathrm{p} / \mathrm{yr}$ in 2008 to $0 \mathrm{ib} / \mathrm{p} / \mathrm{yr}$ in 2012, whereas those of $A n$. arabiensis increased approximately four times from 30.58 in 2008 to 110.9 in 2012 and that of $A n$. funestus s.s. increased 11 times from 10.86 in 2008 to 115.10 in 2012.

Overall, the level of malaria transmission in the study villages markedly decreased with time from an EIR of $78.14 \mathrm{ib} / \mathrm{p} / \mathrm{yr}$ in 2008 to $31.05 \mathrm{ib} / \mathrm{p} / \mathrm{yr}$ in 2011 but overwhelmingly increased to $226 \mathrm{ib} / \mathrm{p} / \mathrm{yr}$ in 2012, approximately seven times more than in the previous year (Table 1).

\section{Anopheles arabiensis and Anopheles funestus insecticide susceptibility tests}

In the WHO bioassay testing, as the results indicated (Figure 3), An. funestus was fully susceptible to deltamethrin (100\% mortality) with reduced susceptibility to permethrin (93\%), and lambda cyhalothrin (91\%) and confirmed resistance to DDT (86\%) in year 2013. In 2014, An. funestus was resistant to permethrin (65\%), lambda cyhalothrin (74\%), bendiocarb (65\%), and even to deltamethrin (87\%) to which it was fully susceptible in 2013. Mortality in control tubes was $4 \%$ in both testing rounds. All tested mosquitoes were amplified as An. funestus, using PCR.

In year 2013, An. arabiensis was fully susceptible to bendiocarb (100\% mortality) and deltamethrin (98.3\%), reduced susceptibility against DDT (97\%), and confirmed resistance to permethrin (83.3\%) and lambda cyhalothrin (78\%), with a control mortality of $0 \%$ across all test concentrations. Similar levels of resistance were maintained across tested diagnostic concentrations in year 2014, whereby the mosquitoes were fully susceptible to bendiocarb (98\% mortality) and resistant to deltamethrin (64\%), permethrin (77\%), and lambda cyhalothrin $(42 \%)$, with a control mortality of $0 \%$ across all test concentrations.

\section{Discussion}

This study provides substantial information on malaria vector dynamics and their contribution to malaria transmission in rural southern Tanzania over a five year period. Consistent with other studies, which have documented a shift in malaria vector composition and a change in malaria transmission dynamics seemingly as a result of extensive use of LLINs $[4,5,36]$, this study reports a steady decrease to undetectable levels of $A n$. 

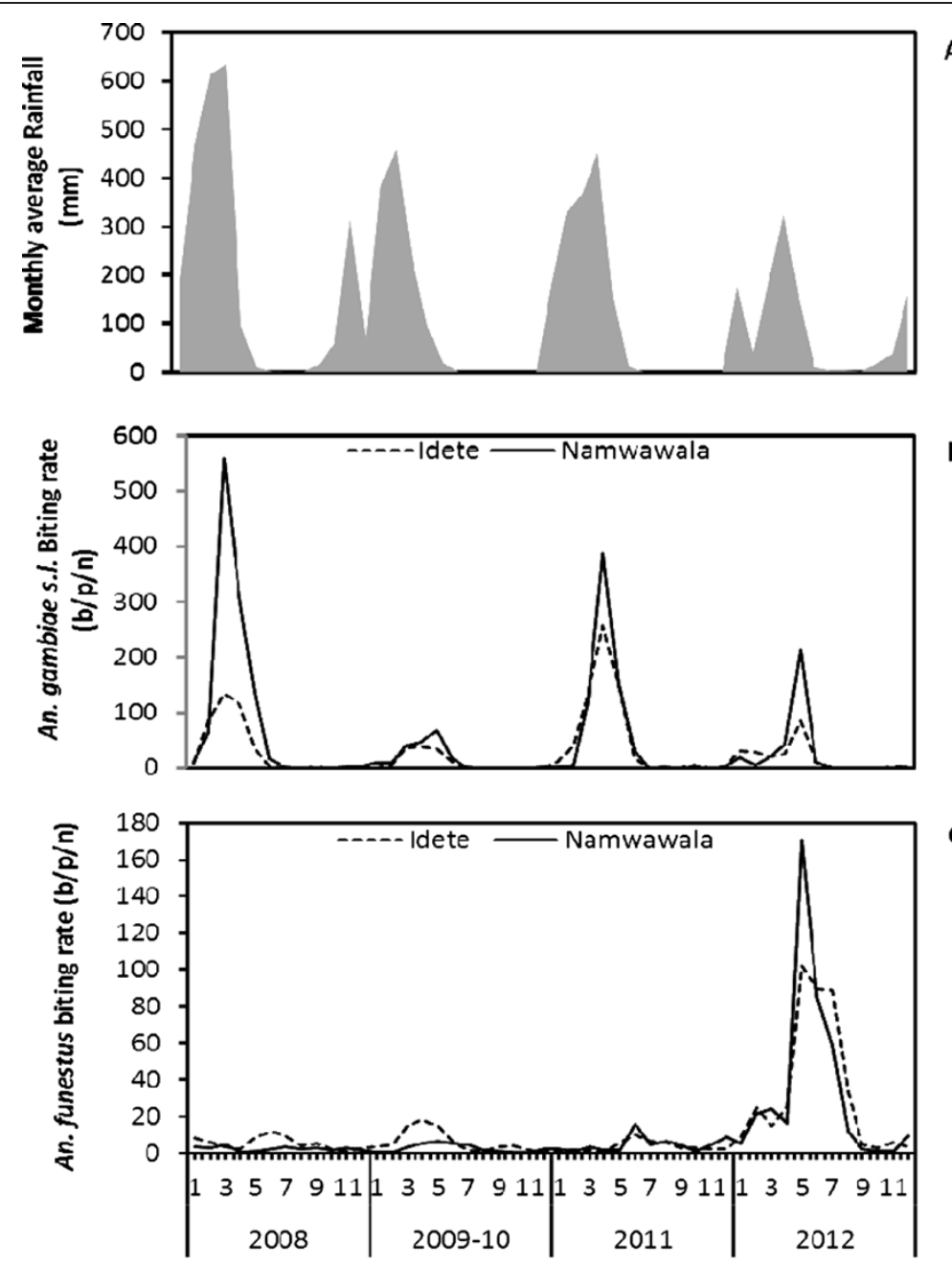

Months, Year

Figure 2 Monthly average rainfall in the Kilombero Valley. (A) estimated using CDC monthly biting rates, adjusted by dividing by species-specific relative efficiency of 0.3 and 0.68 for An. gambiae s.I. (B) and An. funestus (C), respectively [21], in Idete and Namwawala villages over time.

gambiae s.s. with steady increase in the proportion of its sibling species $A n$. arabiensis and a surge in the abundance of An. funestus s.s. in year 2012.

Anopheles gambiae s.s. prefers to feed and rest inside houses. This makes it more vulnerable to insecticides applied to nets (LLINs) and walls (indoor residual spraying (IRS)) while An. arabiensis, with its opportunistic feeding behaviour both on humans and animals [12,32] and its potential to rest outside human dwellings, make it less affected by LLINs. Although, lack of outdoor mosquito collections was a major limitation of this study in explaining the shift in biting periodicity and outdoor biting, it has been recently documented elsewhere that An. arabiensis and An. funestus [25,37] display a behavioural avoidance to contact LLINs by feeding outdoors in early part of the evening which might increase its chance to survive current interventions.
A significant increase in An. funestus abundance and EIR in 2012 is demonstrated. This shift poses great concern in malaria control efforts due to its efficiency in transmitting malaria. Historically the control of $A n$. funestus s.s. was successful through extensive IRS, taking advantage of its highly anthropophagic and endophilic behaviour, using dieldrin in Pare, Taveta, northern Tanzania [38,39] Malindi on the coast of Kenya, using DDT [40] as well as in South Africa [41]. This is partly because they spend a longer time on insecticide-treated materials [42]. However, the vector eventually resurged six years later due to a lack of IRS programme continuity and consolidation [40,43]. A similar scenario was expected in this particular region, where usage of LLINs is high $[3,44]$.

The steady increase in $A n$. funestus population density, despite extensive usage of LLINs in the study area, may 


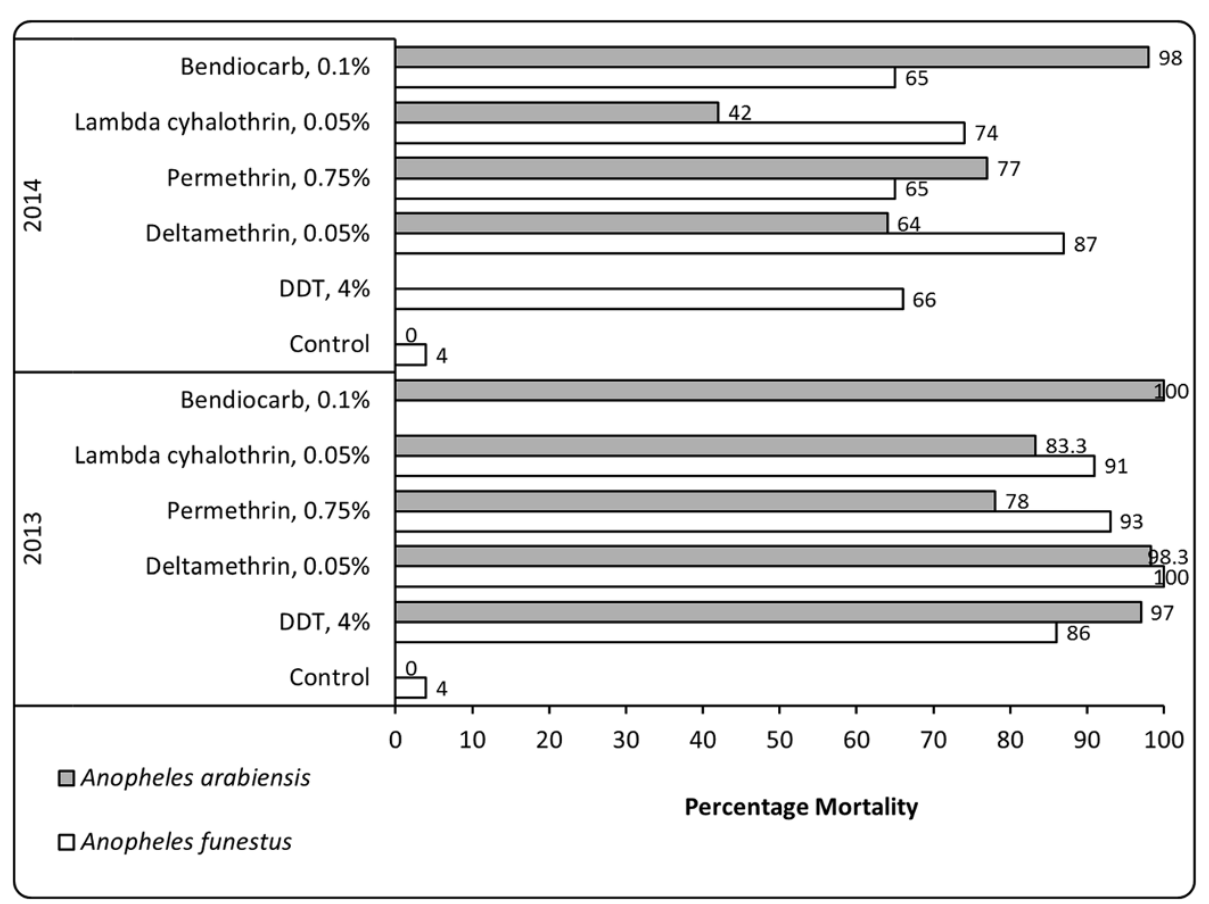

Figure 3 Results of WHO bioassay test for insecticide susceptibility status of wild female Anopheles funestus (white bars) and Anopheles arabiensis (grey bars) from the study sites in the Kilombero Valley, Tanzania, in January 2013 and June 2014. The graph shows percentage 24 hours mortality rate after a one-hour exposure to the WHO diagnostic doses of insecticide. The minimum sample size for these assays was 100.

be due to its reduced susceptibility to the insecticides used in LLINs. Recent findings from western Kenya have demonstrated similar phenomenon of resurging $A n$. funestus populations, chiefly being due to resistance development to the pyrethroids used in LLINs [45].

Preliminary findings from this study demonstrated high resistance of An. funestus and An. arabiensis to pyrethroids, deltamethrin, lambda cyhalothrin and permethrin, used in Olyset LLINs, distributed in the study area in June 2011 [3]. Overall, there was great variation of the resistance status between 2013 and 2014 in both species tested; however, the variation was surprisingly huge in An. funestus than An. arabiensis, which might be due to inconsistency in unknown age of the used wild mosquito females [33].

Due to the absence of organochlorine insecticide DDT and carbamate insecticide bendiocarb deployment for malaria vector control in the study area, the source of resistance in mosquitoes to these insecticides remains unknown. Although not tested in this particular study, pyrethroid (DDT and pyrethroid) carbamate cross-resistance was considered to be a probable cause of An. funestus resistance to DDT and bendiocarb, respectively, which has been proved to exist in malaria vectors elsewhere [46,47]. In addition, the continuous and illegitimate use of DDT as a pesticide in agriculture in the region might have contaminated malaria vector breeding habitats and caused physiological resistance in mosquitoes [48].
Pyrethroid resistance in both species has been documented in multiple countries and regions of East Africa [45,49,50], southern Africa [51-54] and West Africa [55-57]. Further detailed studies are urgently required to establish current vector control operational impacts associated with this level of resistance. These findings suggest an increased contribution of these vectors to malaria transmission and hence great threat to the future use of LLINs in controlling these vectors.

The other probable cause for the observed increase in An. funestus population in this study area, which requires further investigation, might be a shift of $A n$. funestus to outdoor and early evening and daytime biting behaviours, which increase their chances to survive and reproduce by feeding on unprotected humans, as recently documented An. funestus behaviours in Benin [58] and Senegal [59], West Africa.

In this study, both An. funestus and An. gambiae s.l. vector abundance varied with season. Increases in $A n$. gambiae s.l. densities are facilitated by a wide range of ephemeral, sunlit, breeding habitats, such as hoof prints, rice puddles and ground depressions created during the rainy season $[18,60]$. The temporary nature of these habitats tends to reduce predation rate but also allows quick development of the juvenile stages, which results in An. gambiae s.l. dominating during the rainy season [18]. On the contrary, An. funestus prefer vegetated semi-permanent and permanent breeding habitats, such 
as swamps and large ponds [18]. Anopheles funestus remained at a reasonable and detectable density across the rainy and dry seasons in the study areas and were significantly more abundant than An. gambiae s.l. in the dry season, probably due to their breeding habitat stability against desiccation [61].

Irrespective of seasonal variation in vector abundance, An. funestus s.s., An. gambiae s.s. and An. arabiensis were all-important malaria vectors in the study area [12]. Despite high abundance of An. arabiensis and a higher EIR between 2008 and 2010, An. funestus contributed a relatively higher or equal EIR in 2011 and 2012. Historically, An. funestus has displayed high sporozoite prevalence [62] similar to that observed in this study and in a recent study conducted in neighbouring villages within the valley (Kaindoa et al., unpublished). This trend of increase in abundance and high sporozoite prevalence of $A n$. funestus has been also observed in Asembo district, western Kenya [45] and so appears to represent a trend across several regions of East Africa.

The huge increase in potential malaria transmission in 2012 (EIR $=226)$ coincided with an increase in abundance and sporozoite rates in An. funestus as it did in a neighbouring village in the valley $(E I R=467$ ) (Kaindoa et al., unpublished). The substantial increase in $A n$. funestus and its reduced susceptibility to pyrethroids poses a serious threat that needs attention from vector control stakeholders. A separate study in West Africa also reported a rebound in malaria transmission partly being caused by resistance development in An. gambiae to pyrethroids [63].

A previous study has shown that despite high coverage and usage of LLINs, a high proportion of mosquitoes still enter houses [64]. Therefore, the increase in $A n$. funestus, particularly in the dry season, is likely to exacerbate the problem. Therefore, new strategies to address resistance and outdoor biting behaviour in the early part of the evening as displayed by An. funestus and $A n$. arabiensis are required. This can be achieved through improving the LLINs; for instance, recent development of nets which can target multiple resistant mosquitoes, Olyset ${ }^{\oplus}$ Plus [65], and by targeting vectors while outdoors using non-resistant compounds, either through larval source management in the dry season via autodissemination of insect juvenile hormone, e.g., pyriproxyfen [66,67], or by mosquito sterilization with pyriproxyfen [68], and killing them with toxic sugar-baited traps [69], non-chemical electric grid [70] and odourbaited traps [71].

\section{Conclusion}

This study shows that An. funestus and An. arabiensis are important malaria vectors sustaining malaria transmission, with a substantial increase in An. funestus and drastic reduction in $A n$. gambiae s.s. in the year 2012. Malaria transmission significantly declined from 2008 to 2011 and rebounded in 2012 coinciding with an increased role of $A n$. arabiensis and An. funestus in malaria transmission. Although fully susceptible to deltamethrin, An. arabiensis and An. funestus were found to be resistant and with reduced susceptibility to permethrin pyrethroid used for LLINs, respectively. These findings call for complementary vector control tools, robust vector surveillance systems and an insecticide resistance management plan to complement and preserve the efficacy of LLINs.

\section{Competing interests}

The authors have declared no competing interests.

\section{Authors' contributions}

DWL, CH, SD, SM, PJM, and GJD proposed the study hypothesis and experimental design. DWL and SSK performed statistical analysis and wrote the first draft of the manuscript. DWL supervised the surveillance and data collection. DWL, SM and PJM wrote the manuscript. All authors read and approved the final manuscript.

\section{Acknowledgements}

The study was funded by the Bill and Melinda Gates Foundation through the Global Health Program (Seattle, USA), Grant number OPP52644 and the Addessium Foundation (Reeuwijk, The Netherlands). We are grateful to the community in the villages of Namwawala and Idete for their participation in the study. We particularly thank our colleagues who helped in field data collection and processing: Japhet Kihonda, Peter Pazia, Daniel Lugiko, Nuru Nchimbi, Josephat Kihonda, Matrida Kideule, Cecilia Mchope, and Monica Mpingwa. We thank Deogratius Roman and Salum Aziz for laboratory sample analysis, and Japhet Kihonda for conducting insecticide resistance susceptibility tests, Nico Govella and William Kisinza for supplying insecticides diagnostic concentrations and providing guidance for bioassay testing.

\section{Author details}

${ }^{1}$ Environmental Health and Ecological Sciences Thematic Group, Ifakara Health Institute, PO Box 53, Ifakara, Tanzania. Vector Biology Department, Liverpool School of Tropical Medicine, Pembroke Place, Liverpool L3 5QA, UK. ${ }^{3}$ Division of Biomedical and Life Sciences, Lancaster University, Bailrigg, Lancaster LA1 4YW, UK. ${ }^{4}$ Department of Mathematics, Statistics and Computer Science, Marquette University, Milwaukee, WI 53201-1881, USA. ${ }^{5}$ Department of Epidemiology and Public Health, Swiss Tropical and Public Health Institute, Socintr 57, PO Box, CH-4002, Basel, Switzerland. ' QIMR Berghofer Medical Research Institute, Brisbane, Queensland, Australia.

Received: 4 July 2014 Accepted: 22 August 2014

Published: 24 August 2014

\section{References}

1. Bruce-Chwatt LJ, Garret-Jones C, Weitz B: Ten year study (1955-64) of host selection by Anopheline mosquitoes. Bull World Health Organ 1966, 35:405-439.

2. WHO: World Malaria Report. Geneva, Switzerland: World Health Organization; 2013.

3. Tanzania Commission for AIDS ZAC, National Bureau of Statistics, Office of the Chief Government Statistician, ICF International Calverton MU: Tanzania HIV/AIDS and Malaria Indicator Survey 2011-12. Tanzania: Dar es Salaam: TACAIDS, ZAC, NBS, OCGS, and Macro International Inc Dar es Salaam; 2013.

4. Bayoh MN, Mathias DK, Odiere MR, Mutuku FM, Kamau L, Gimnig JE, Vulule JM, Hawley WA, Hamel MJ, Walker ED: Anopheles gambiae: historical population decline associated with regional distribution of insecticide-treated bed nets in western Nyanza Province. Kenya Malar J 2010, 9:62.

5. Mwangangi JM, Mbogo CM, Orindi BO, Muturi EJ, Midega JT, Nzovu J, Gatakaa H, Githure J, Borgemeister C, Keating J: Shifts in malaria vector species composition and transmission dynamics along the Kenyan coast over the past 20 years. Malar J 2013, 12:13. 
6. Okumu FO, Kiware SS, Moore SJ, Killeen GF: Mathematical evaluation of community level impact of combining bed nets and indoor residual spraying upon malaria transmission in areas where the main vectors are Anopheles arabiensis mosquitoes. Parasit Vectors 2013, 6:1-24.

7. Mzilahowa T, Hastings IM, Molyneux ME, McCall PJ: Entomological indices of malaria transmission in Chikhwawa district. Southern Malawi Malar J 2012, 11:380.

8. Sinka ME, Bangs MJ, Manguin S, Rubio-Palis Y, Chareonviriyaphap T, Coetzee M, Mbogo CM, Hemingway J, Patil AP, Temperley WH: A global map of dominant malaria vectors. Parasit Vectors 2012, 5:69.

9. Coetzee M, Craig M, Le Sueur D: Distribution of African malaria mosquitoes belonging to the Anopheles gambiae complex. Parasitol Today 2000, 16:74-77.

10. Gillies M, Coetzee M: A Supplement of the Anophelinae of Africa South of the Sahara (Afrotropical region). South African Medical Research Institute: Johannesburg; 1987.

11. Russell TL, Lwetoijera DW, Maliti D, Chipwaza B, Kihonda J, Charlwood D, Smith TA, Lengeler C, Mwanyangala MA, Nathan R, Knols BGJ, Takken W, Killeen GF: Impact of promoting longer-lasting insecticide treatment of bed nets upon malaria transmission in a rural Tanzanian setting with pre-existing high coverage of untreated nets. Malar J 2010, 9:187.

12. Corbel V, N'Guessan R, Brengues C, Chandre F, Djogbenou L, Martin T, Akogbeto M, Hougard JM, Rowland M: Multiple insecticide resistance mechanisms in Anopheles gambiae and Culex quinquefasciatus from Benin, West Africa. Acta Trop 2007, 101:207-216.

13. N'Guessan R, Corbel V, Akogbeto M, Rowland M: Reduced efficacy of insecticide-treated nets and indoor residual spraying for malaria control in pyrethroid resistance area, Benin. Emerg Infect Dis 2007, 13:199-206.

14. Muriu SM, Muturi EJ, Shililu JI, Mbogo CM, Mwangangi JM, Jacob BG, Irungu LW, Mukabana RW, Githure Jl, Novak RJ: Host choice and multiple blood feeding behaviour of malaria vectors and other anophelines in Mwea rice scheme. Kenya Malar J 2008, 7:43.

15. Tirados I, Costantini C, Gibson G, Torr SJ: Blood-feeding behaviour of the malarial mosquito Anopheles arabiensis: implications for vector control. Med Vet Entomol 2006, 20:425-437.

16. Kitau J, Oxborough RM, Tungu PK, Matowo J, Malima RC, Magesa SM, Bruce J, Mosha FW, Rowland MW: Species shifts in the Anopheles gambiae complex: do LLINs successfully control Anopheles arabiensis? PLoS One 2012, 7:e31481.

17. White G, Magayuka SA, Boreham PFL: Comparative studies on sibling species of the Anopheles gambiae Giles complex (Dipt., Culicidae): bionomics and vectorial activity of species A and species B at Segera, Tanzania. Bull Entomol Res 1972, 62:295-317.

18. Gillies M, de Meillon B: The Anophelini of Africa South of the Sahara (Ethiopian Zoogeographical Region). 2nd edition. Johannesburg: South African Institute of Medical Research; 1968.

19. Mendis C, Jacobsen JL, Gamage-Mendis A, Bule E, Dgedge M, Thompson R, Cuamba N, Barreto J, Begtrup K, Sinden RE, Hogh B: Anopheles arabiensis and An. funestus are equally important vectors of malaria in Matola coastal suburb of Maputo, southern Mozambique. Med Vet Entomol 2000, 14:171-180

20. Smith T, Charlwood JD, Kihonda J, Mwankusye S, Billingsley P, Meuwissen J, Lyimo E, Takken W, Teuscher T, Tanner M: Absence of seasonal variation in malaria parasitaemia in an area of intense seasonal transmission. Acta Trop 1993, 54:55-72

21. Killeen G, Tami A, Kihonda J, Okumu F, Kotas M: Cost-sharing strategies combining targeted public subsidies with private-sector delivery achieve high bednet coverage and reduced malaria transmission in Kilombero Valley, southern Tanzania. BMC Infect Dis 2007, 7:121.

22. Alba S, Hetzel MW, Nathan R, Alexander M, Lengeler C: Assessing the impact of malaria interventions on morbidity through a community-based surveillance system. Int J Epidemiol 2011, 40:405-416.

23. Mulligan JA, Yukich J, Hanson K: Costs and effects of the Tanzanian national voucher scheme for insecticide-treated nets. Malar J 2008, 7:32.

24. Renggli S, Mandike R, Kramer K, Patrick F, Brown NJ, McElroy PD, Rimisho W, Msengwa A, Mnzava A, Nathan R: Design, implementation and evaluation of a national campaign to deliver 18 million free long-lasting insecticidal nets to uncovered sleeping spaces in Tanzania. Malar J 2013, 12:85.

25. Russell T, Govella N, Azizi S, Drakeley C, Kachur SP, Killeen G: Increased proportions of outdoor feeding among residual malaria vector populations following increased use of insecticide-treated nets in rural Tanzania. Malar J 2011, 10:80.
26. Schellenberg JRMA, Abdulla S, Nathan R, Mukasa O, Marchant TJ, Kikumbih $\mathrm{N}$, Mushi AK, Mponda H, Minja H, Mshinda H: Effect of large-scale social marketing of insecticide-treated nets on child survival in rural Tanzania. Lancet 2001, 357:1241-1247.

27. Lines JD, Curtis CF, Wilkes TJ, Njunwa KJ: Monitoring human-biting mosquitoes (Diptera: Culicidae) in Tanzania with light-traps hung beside mosquito nets. Bull Entomol Res 1991, 81:77-84.

28. Mboera LE, Kihonda J, Braks MA, Knols BG: Short report: influence of centers for disease control light trap position, relative to a human-baited bed net, on catches of Anopheles gambiae and Culex quinquefasciatus in Tanzania. Am J Trop Med Hyg 1998, 59:595-596.

29. Scott JA, Brogdon WG, Collins FH: Identification of single specimens of the Anopheles gambiae complex by the polymerase chain-reaction. Am J Trop Med Hyg 1993, 49:520-529.

30. Koekemoer $L L$, Kamau L, Hunt RH, Coetzee M: A cocktail polymerase chain reaction assay to identify members of the Anopheles funestus (diptera: culicidae) group. Am J Trop Med Hyg 2002, 6:804-811.

31. Burkot T, Williams J, Schneider I: Identification of Plasmodium falciparum infected mosquitoes by a double antibody enzyme-linked immunosorbent assay. Am J Trop Med Hyg 1984, 33:783-788.

32. Kelly-Hope LA, McKenzie FE: The multiplicity of malaria transmission: a review of entomological inoculation rate measurements and methods across sub-Saharan Africa. Malar J 2009, 8:19.

33. WHO: Test Procedures for Insecticide Resistance Monitoring in Malaria Vector Mosquitoes. Geneva, Switzerland: World Health Organization; 2013:39. www.who.int/entity/malaria/publications/atoz/9789241505154/en/.

34. Chouaibou MS, Chabi J, Bingham GV, Knox TB, N'Dri L, Kesse NB, Bonfoh B, Jamet HV: Increase in susceptibility to insecticides with aging of wild Anopheles gambiae mosquitoes from Côte d'Ivoire. BMC Infect Dis 2012, 12:214.

35. Jones CM, Sanou A, Guelbeogo WM, Sagnon N, Johnson P, Ranson H: Aging partially restores the efficacy of malaria vector control in insecticide-resistant populations of Anopheles gambiae s.l. from Burkina Faso. Malar J 2012, 11:24.

36. Derua YA, Alifrangis M, Hosea KM, Meyrowitsch DW, Magesa SM, Pedersen EM, Simonsen PE: Change in composition of the Anopheles gambiae complex and its possible implications for the transmission of malaria and lymphatic filariasis in north-eastern Tanzania. Malar J 2012, 11:188.

37. Wilkes TJ, Matola YG, Charlwood JD: Anopheles rivulorum, a vector of human malaria in Africa. Med Vet Entomol 1996, 10:108-110.

38. Gillies MT, Smith A: Effect of a residual house-spraying campaign on species balance in the Anopheles funestus group: the replacement of Anopheles gambiae Giles with Anopheles rivulorum leesoni. Bull Entomol Res 1960, 51:248-252.

39. Smith A: Malaria in the Taveta area of Kenya and Tanzania. Part IV. Entomological findings six years after the spraying period. East Afr Med J 1966, 43:7-18

40. Gillies MT, Furlong M: An investigation into the behaviour of Anopheles parensis Gillies at Malindi on the coast of Kenya. Bull Entomol Res 1964, 55:1-16.

41. Sharp BL, Kleinschmidt I, Streat E, Maharaj R, Barnes KI, Durrheim DN, Ridl FC, Morris N, Seocharan I, Kunene S, La Grange JJP, Mthembu JD, Maartens $F$, Martin CL, Barreto A: Seven years of regional malaria control collaboration - Mozambique, South Africa, and Swaziland. Am J Trop Med Hyg 2007, 76:42-47.

42. Davidson G: Experiments on the effects of residual insecticides in houses against Anopheles gambiae and An. funestus. Bull Entomol Res 1953, 44:231-254.

43. The malERA Consultative Group on Vector Control: A research agenda for malaria eradication: vector control. PLoS Med 2011, 8:e1000401.

44. Koenker HM, Yukich JO, Mkindi A, Mandike R, Brown N, Kilian A, Lengeler C: Analysing and recommending options for maintaining universal coverage with long-lasting insecticidal nets: the case of Tanzania in 2011. Malar J 2013, 12:150

45. McCann RS, Ochomo O, Bayoh N, Vulule JM, Gimnig JE, Walker ED Reemergence of Anopheles funestus as a vector of Plasmodium falciparum in western Kenya after long-term implementation of insecticide-treated bed nets. Am J Trop Med Hyg 2014, 90:597-604.

46. Brooke B, Kloke G, Hunt R, Koekemoer L, Tem E, Taylor M, Small G, Hemingway J, Coetzee M: Bioassay and biochemical analyses of insecticide resistance in southern African Anopheles funestus (Diptera: Culicidae). Bull Entomol Res 2001, 91:265-272. 
47. Protopopoff N, Matowo J, Malima R, Kavishe R, Kaaya R, Wright A, West PA, Kleinschmidt I, Kisinza W, Mosha FW: High level of resistance in the mosquito Anopheles gambiae to pyrethroid insecticides and reduced susceptibility to bendiocarb in north-western Tanzania. Malar J 2013, 12:149.

48. Nkya TE, Akhouayri I, Kisinza W, David J-P: Impact of environment on mosquito response to pyrethroid insecticides: facts, evidences and prospects. Insect Biochem Molec Biol 2013, 43:407-416.

49. Matambo T, Abdalla H, Brooke B, Koekemoer L, Mnzava A, Hunt R, Coetzee $\mathrm{M}$ : Insecticide resistance in the malarial mosquito Anopheles arabiensis and association with the kdr mutation. Med Vet Entomol 2007, 21:97-102.

50. Morgan JC, Irving H, Okedi LM, Steven A, Wondji CS: Pyrethroid resistance in an Anopheles funestus population from Uganda. PLoS One 2010, 5:e11872.

51. Hargreaves K, Hunt RH, Brooke BD, Mthembu J, Weeto MM, Awolola TS, Coetzee M: Anopheles arabiensis and An. quadriannulatus resistance to DDT in South Africa. Med Vet Entomol 2003, 17:417-422.

52. Casimiro S, Coleman M, Mohloai P, Hemingway J, Sharp B: Insecticide resistance in Anopheles funestus (Diptera: Culicidae) from Mozambique. $J$ Med Entomol 2006, 43:267-275.

53. Kloke RG, Nhamahanga $\mathrm{E}$, Hunt RH, Coetzee M: Vectorial status and insecticide resistance of Anopheles funestus from a sugar estate in southern Mozambique. Parasit Vectors 2011, 4:16.

54. Wondji CS, Coleman M, Kleinschmidt I, Mzilahowa T, Irving H, Ndula M, Rehman A, Morgan J, Barnes KG, Hemingway J: Impact of pyrethroid resistance on operational malaria control in Malawi. Proc Natl Acad SCi 2012, 109:19063-19070.

55. Okoye PN, Brooke BD, Koekemoer LL, Hunt RH, Coetzee M: Characterisation of DDT, pyrethroid and carbamate resistance in Anopheles funestus from Obuasi, Ghana. Trans R Soc Trop Med Hyg 2008, 102:591-598.

56. Ranson H, Guessan R, Lines J, Moiroux N, Nkuni Z, Corbel V: Pyrethroid resistance in African anopheline mosquitoes: what are the implications for malaria control? Trends Parasitol 2011, 27:91-98.

57. Djouaka R, Irving H, Tukur Z, Wondji CS: Exploring mechanisms of multiple insecticide resistance in a population of the malaria vector Anopheles funestus in Benin. PLoS One 2011, 6:e27760.

58. Moiroux N, Gomez MB, Pennetier C, Elanga E, Djènontin A, Chandre F,

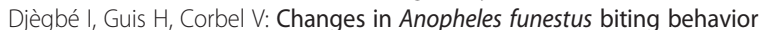
following universal coverage of long-lasting insecticidal nets in Benin. J Infect Dis 2012, 206:1622-1629.

59. Sougoufara S, Diédhiou SM, Doucouré S, Diagne N, Sembène PM, Harry M, Trape J-F, Sokhna C, Ndiath MO: Biting by Anopheles funestus in broad daylight after use of long-lasting insecticidal nets: a new challenge to malaria elimination. Malar J 2014, 13:125.

60. Minakawa N, Sonye G, Mogi M, Yan G: Habitat characteristics of Anopheles gambiae s.s. larvae in a Kenyan highland. Med Vet Entomol 2004, 18:301-305.

61. Charlwood JD, Vij R, Billingsley PF: Dry season refugia of malaria-transmitting mosquitoes in a dry savannah zone of east Africa. Am J Trop Med Hyg 2000, 62:726-732.

62. Charlwood J, Smith T, Kihonda J, Heiz B, Billingsley P, Takken W: Density independent feeding success of malaria vectors (Diptera: Culicidae) in Tanzania. Bull Entomol Res 1995, 85:29-35.

63. Trape J, Tall A, Diagne N, Ndiath O, Ly AB, Faye J, Dieye-Ba F, Roucher C, Bouganali C, Badiane A, Sarr FD, Mazenot C, Touré-Baldé A, Raoult D, Druilhe P, Puijalon OM, Rogier C, Sokhna C: Malaria morbidity and pyrethroid resistance after the introduction of insecticide -treated bednets and artemisinin-based combination therapies: a longitudinal study. Lancet Infect Dis 2011, 11:925-932.

64. Gatton ML, Chitnis N, Churcher T, Donnelly MJ, Ghani AC, Godfray HCJ, Gould F, Hastings I, Marshall J, Ranson H, Rowland M, Shaman J, Linday SW: The importance of mosquito behavioural adaptations to malaria control in Africa. Evolution 2013, 67:1218-1230.

65. Pennetier C, Bouraima A, Chandre F, Piameu M, Etang J, Rossignol M, Sidick I, Zogo B, Lacroix M-N, Yadav R: Efficacy of Olyset ${ }^{\oplus}$ Plus, a new long-lasting insecticidal net incorporating permethrin and piperonil-butoxide against multi-resistant malaria vectors. PLoS One 2013, 8:e75134.

66. Devine GJ, Zamora Perea E, Killeen GF, Stancil JD, Clark SJ, Morrison AC: Using adult mosquitoes to transfer insecticides to Aedes aegypti larval habitats. Proc Natl Acad Sci U S A 2009, 106:11530-11534.

67. Lwetoijera DW, Harris C, Kiware S, Dongus S, Devine GJ, McCall PJ, Majambere S: Effective autodissemination of pyriproxyfen to breeding sites by the exophilic malaria vector Anopheles arabiensis in semi-field settings in Tanzania. Malar J 2014, 13:161

68. Lwetoijera DW, Harris C, Kiware SS, Killeen GF, Dongus S, Devine GJ, Majambere S: Comprehensive sterilization of malaria vectors using pyriproxyfen: a step closer to malaria elimination. Am J Trop Med Hyg 2014, 90:852-855.

69. Muller GC, Schlein Y: Efficacy of toxic sugar baits against adult cistern-dwelling Anopheles claviger. Trans R SocTrop Med Hyg 2008, 102:480-484.

70. Majambere S, Masue D, Mlacha Y, Govella NJ, Magesa SM, Killeen GF: Advantages and limitations of commercially available electrocuting grids for studying mosquito behaviour. Parasit Vectors 2013, 6:53.

71. Matowo NS, Moore J, Mapua S, Madumla EP, Moshi IR, Kaindoa EW, Mwangungulu SP, Kavishe DR, Sumaye RD, Lwetoijera DW, Okumu FO: Using a new odour-baited device to explore options for luring and killing outdoor-biting malaria vectors: a report on design and field evaluation of the Mosquito Landing Box. Parasit Vectors 2013, 6:137.

doi:10.1186/1475-2875-13-331

Cite this article as: Lwetoijera et al:: Increasing role of Anopheles funestus and Anopheles arabiensis in malaria transmission in the Kilombero Valley, Tanzania. Malaria Journal 2014 13:331

\section{Submit your next manuscript to BioMed Central and take full advantage of:}

- Convenient online submission

- Thorough peer review

- No space constraints or color figure charges

- Immediate publication on acceptance

- Inclusion in PubMed, CAS, Scopus and Google Scholar

- Research which is freely available for redistribution 